\title{
Deformation Analysis of Wood Cutting Set-upusing ANSYS
}

\author{
Priyadarshani Gaikwad, Komal Gund, Kulsum Kazi, Bhairavi Fund, Pravin S. Kachare
}

\begin{abstract}
Now a day's machines are very expensive and having high maintenance and as there is increase in technology in daily activity the manually operated hydraulic wood cutting machine is used. The wood cutting tool is important element for cutting wood into small pieces and which reduces the human effort. It is manually operated machine which reduces the human effort. This is performed in order to improve the quality, efficiency and reduction in cost. The hydraulic wood cutter is the wood cutting machine which is used to cut the wood into small pieces. The wood cutting tool is the main element of the wood cutting device. In this paper deformation analysis of wood cutting tool for variable load is carried out. The deformation analysis is carried out by varying the load acting on the wood cutting tool. The deformation analysis is performed by using ANSYS 15.0. The ANSYS Workbench is an intuitive up-front analysis tool that is used in conjunction with CAD system. ANSYS is a finite element analysis tool for structural analysis which includes linear, nonlinear and dynamic studies. It provides the equation solver for wide range of mechanical problem solvers. For deformation analysis the ANSYS Workbench software is used.In this deformation analysis, it is observed that the deformation increases with increase in load. The deformation analysis is carried out for $200 \mathrm{kN}, 300 \mathrm{kN}, 500 \mathrm{kN}$ forces on tool which gives deformation in tool element.The simulation for analysis of the deformation behavior wood cutting tool at different loads like 200 to $500 \mathrm{KN}$ at an interval of $100 \mathrm{KN}$ is analyzed. As load increases on the cutting tool the deformation also increases.
\end{abstract}

Index Terms - wood cutting tool, deformation, supporting member.

\section{INTRODUCTION}

As we know in India there is primary source of energy is fire wood. Firewood is wooden material which utilized for fuel it has two types hardwood and softwood. Hydraulic wood cutter is a machine which used for cutting the woods. A wood cutting tool is used for splitting fire wood from soft wood that

Priyadarshani Gaikwad, Mechanical Department, SVERI's College of Engineering, Pandharpur, India

KomalGund,Mechanical Department, SVERI's College of Engineering, Pandharpur, India

Kulsum Kazi, Mechanical Department, SVERI's College of Engineering, Pandharpur, India

Bhairavi Fund, Mechanical Department, SVERI's College of Engineering, Pandharpur, India

Pravin Kachare, Mechanical Department, SVERI's College of Engineering, Pandharpur, India has been cut into a section using hydraulic unit (hydraulic jack). It is most commonly used machine for splitting the wood which reduces the human effort. Hydraulic jack is used to lifting heavy loads by application of much smaller force; it works on Pascal's theory, which states that "when pressure is applied on fluid in enclosed system, the pressure through the system is always remain constant."'In hydraulic unit the force generation, transmission and amplification are achieved by using fluid under pressure. Some of the researchers have reported the work related to construction and design of log splitter [1-3]. Various researchers have reported the study related to performance analysis of various components like microchannels, hydrodynamic bearings using softwares like ANSYS, Comsol Multiphysics, etc.[4-7].In this paper, deformation analysis of wood cutting tool is carried out. Firstly,the design of the tool and supporting member in solid work is performed and further imported the geometry in ANSYS Workbench. ANSYS is used for analysis of different component. The aim is to reduce weight of hydraulic wood cutting element without compromising on the quality. The deformation analysis is carried out for variable load. The result observed as the tool is mesh independent and as the load increases deformation increases.

\section{METHODOLOGY}

\section{A. Assumption}

1. Material is linear.

2. Material behavior is isotropic.

\section{B. Model Development}

The wood cutting tool is made up of mild steel material. It consists of two L angle $(40 * 40 * 6) \mathrm{mm}$ having length $48 \mathrm{~mm}$ each and one square pipe $(40 * 40 * 3) \mathrm{mm}$. The cutting tool is welded to a plate and bolted to a assembly as shown in fig. The solid work is used for the modeling of wood cutting tool. Firstly, the model is developed in the solid work software. The whole model is made for the deformation analysis. The model developed in solid work is extracted in ANSYS Workbench. ANSYS Workbench is a finite element analysis tool for structural analysis including linear, nonlinear and dynamic studies. The ANSYS Workbench is provides the equation solver for wide range of mechanical problems. The model in solid work is then extracted into the ANSYS Workbench and expressed in the figure 1 


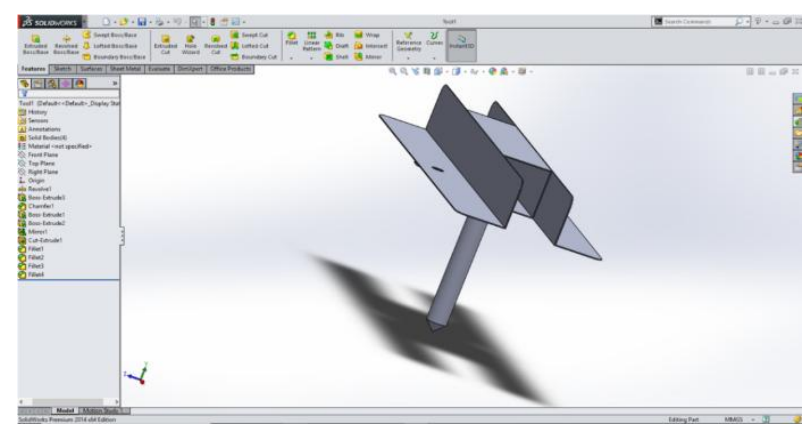

Figure 1 Model in solid work.

\section{ANALYSIS USING ANSYS}

ANSYS is a finite element analysis tool for structural analysis, including linear, nonlinear and dynamic studies.it provides the equation solvers for wide range of mechanical problem solver.ANSYS software is used to design products as well as to create simulations that test temperature distribution, fluid movements, and electromagnetic properties, stress, deformation .For deformation analysis of variable load acting on wood cutter tool and on its supporting member ANSYS 15.0 is used.The model designed in the solid works is imported in the ANSYS 15.0 for analysis.

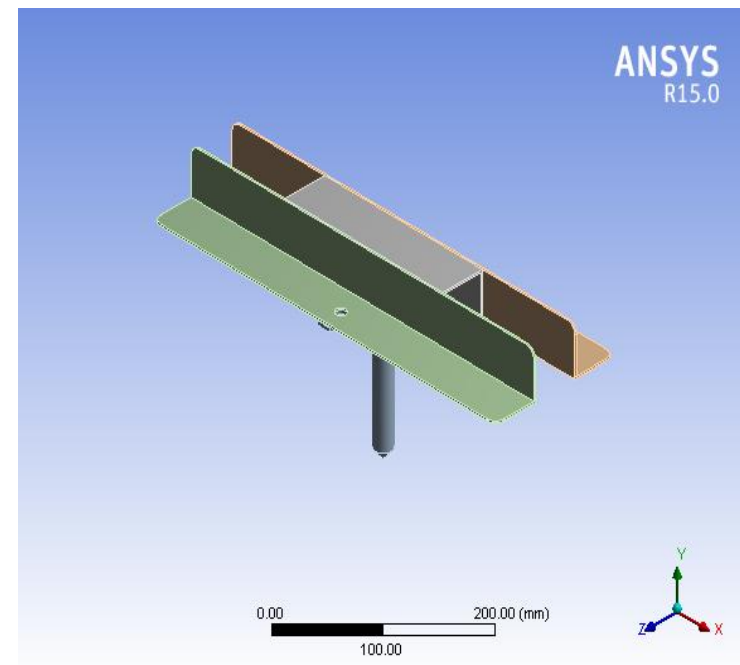

Figure 2. Model in ANSYS Workbench

Input condition: Point load at the tip of tool is given.

Boundary condition: Four faces of L-shape angles are fixed.

\section{MESH INDEPENDENT TEST (GRID INDEPENDENT TEST)}

To avoid the effect of enhanced quality of meshing, mesh independent test is required to be performed. The mesh independent test has performed for $200 \mathrm{kN}$ by varying load and number of elements and the various meshing conditions are presented in figures 3 to 6 . The result of mesh independent test is as shown in figure7.

\section{DEFORMATION FOR $200 \mathrm{KN}$}

\begin{tabular}{|l|l|l|l|}
\hline Fig. No. & Nodes & Elements & Deformation \\
\hline a & 63276 & 22271 & 7.313 \\
\hline $\mathrm{b}$ & 82596 & 29288 & 8.336 \\
\hline $\mathrm{c}$ & 123363 & 45250 & 7.702 \\
\hline $\mathrm{d}$ & 183164 & 67354 & 10.349 \\
\hline
\end{tabular}

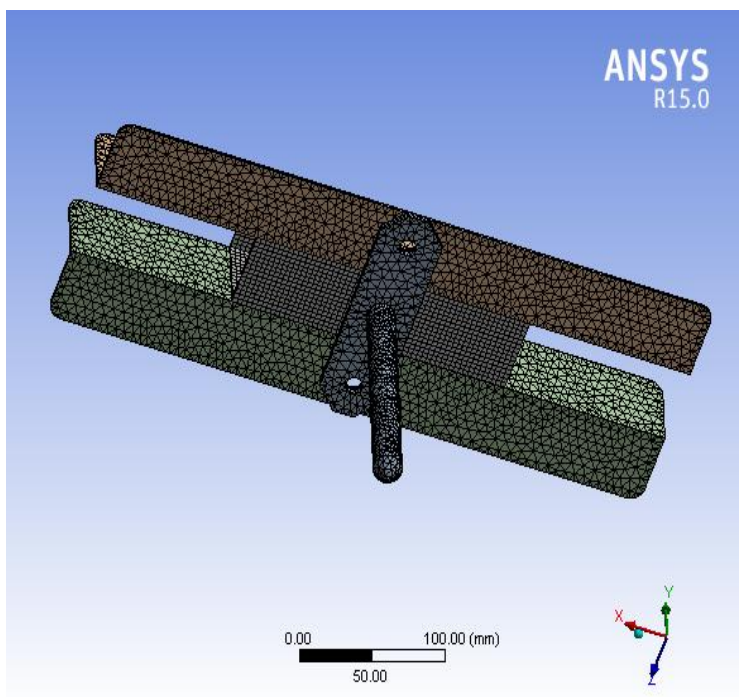

Figure 3

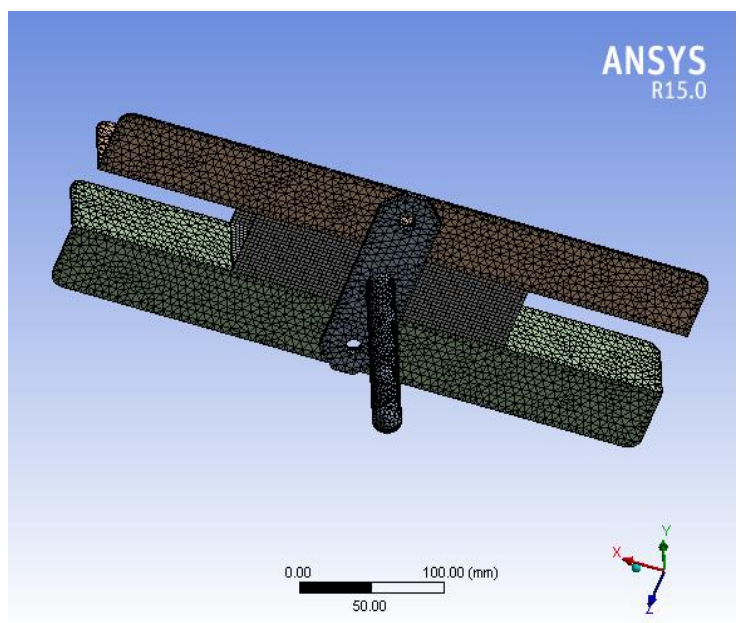

Figure 4

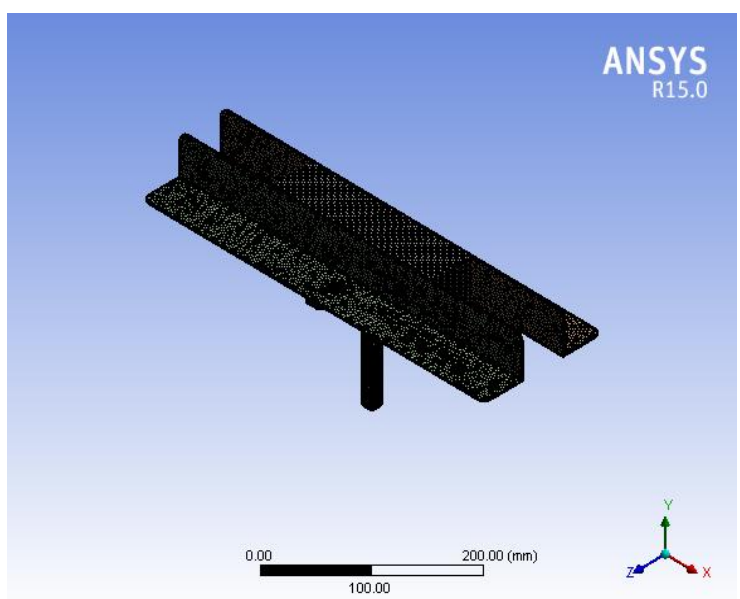

Figure 5 


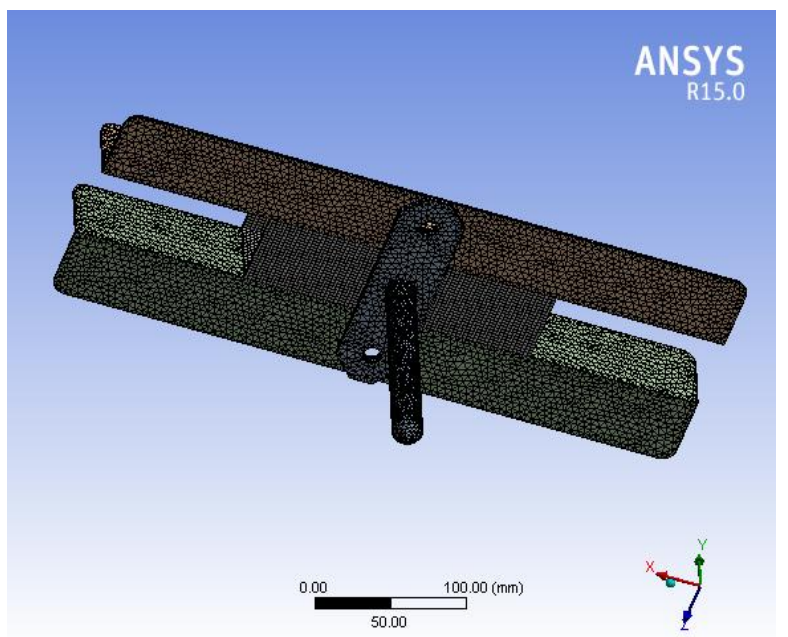

Figure 6

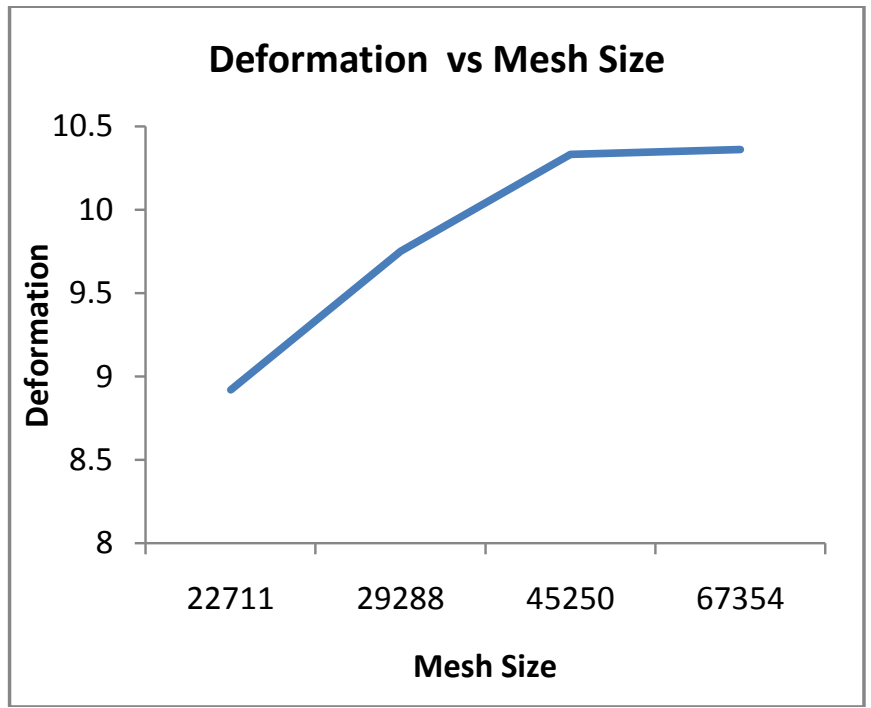

Figure 7Mesh Independence Test

\section{SIMULATION}

After completing the mesh independent test simulation has been carried out for analyzing the wood cutting tool behavior at different forces like $200,300,400$ and $500 \mathrm{kN}$.The simulation is done for the different mesh size.The deformation pattern developed in the wood cutting tool is developed in the ANSYS Workbench.

\section{RESULT AND DISCUSSION}

The simulation for analysis of the deformation behavior wood cutting tool at different loads like 200 to $500 \mathrm{kN}$ at an interval of $100 \mathrm{kN}$ is analyzed. The deformation pattern developed in wood cutting tool after application of load by using ANSYS presented in figure. The deformation is plotted against load and the resulted graph is as shown in figure $12 \mathrm{It}$ is observed from figure that as load increases deformation also increases. The deformation is depending only on the load which is acting on the wood cutting tool. As the load increases gradually by interval of $100 \mathrm{kN}$, deformation varies constantly which is observed from figures 6 to 11 and the results of deformation are presented in figure 12 .

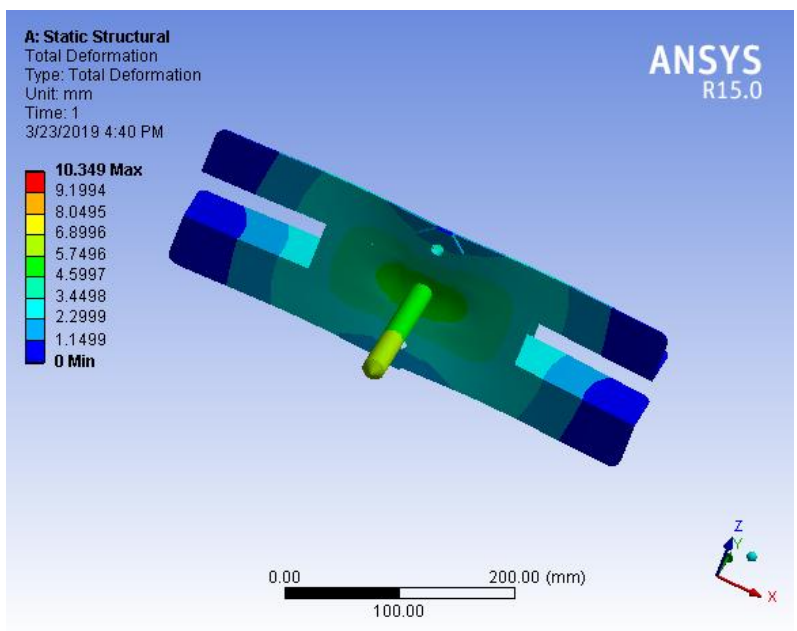

Figure 8 Deformation for $200 \mathrm{kN}$

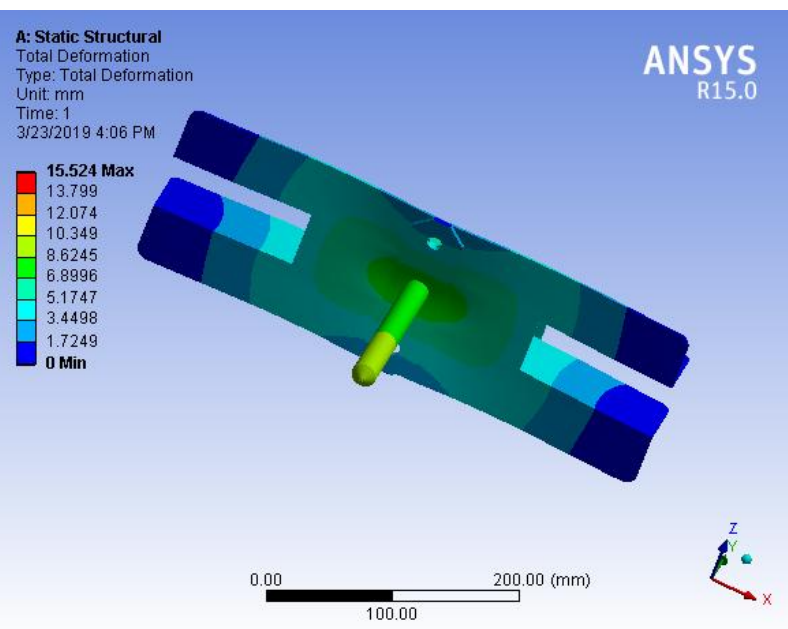

Figure 9 Deformation for $300 \mathrm{kN}$

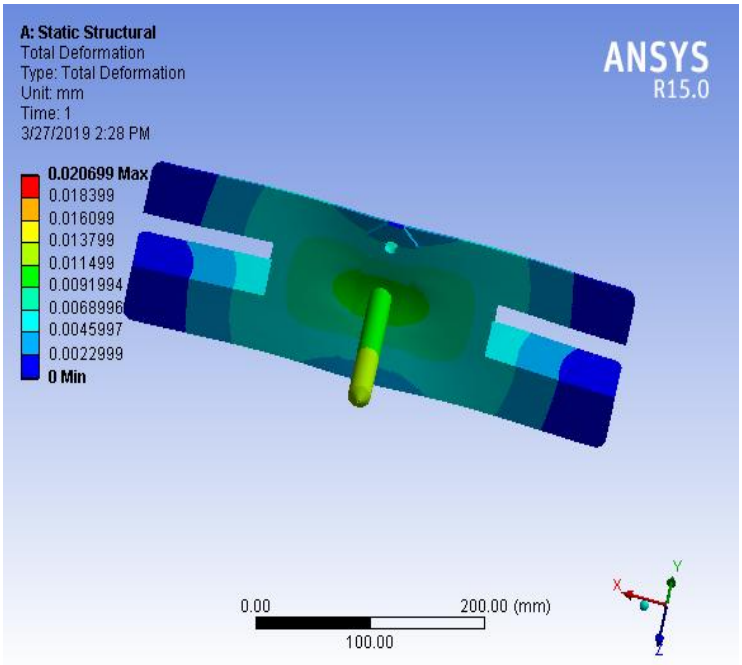

Figure 10 Deformation for $300 \mathrm{kN}$ 


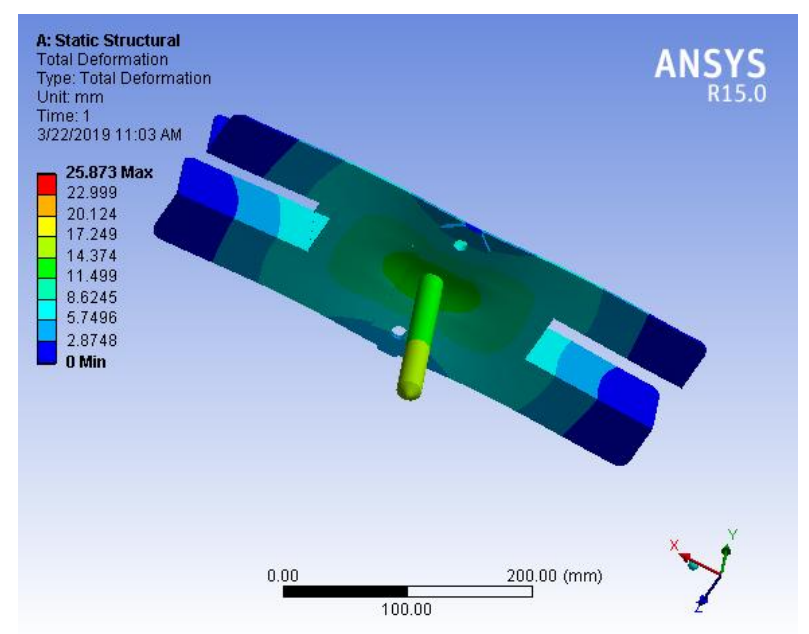

Figure 11 Deformation for $400 \mathrm{kN}$

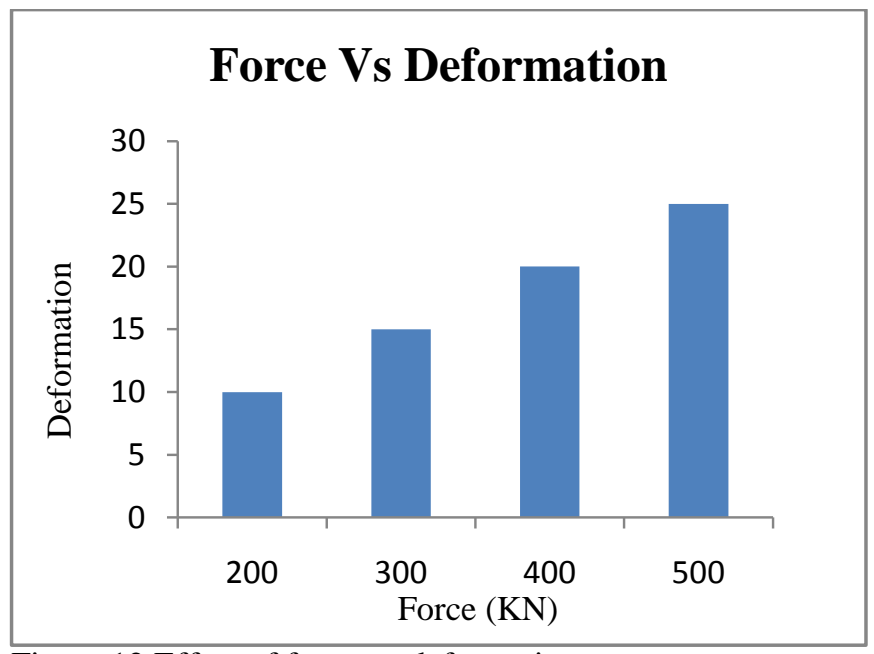

Figure 12 Effect of force on deformation

\section{CONCLUSION}

The wood cutting tool is important element for cutting wood into small pieces which reduces human effort. In this paper wood cutting tool behavior is analyzed at various loading condition and deformation is measured and recorded for different condition. By using deformation analysis, it is proved that the element is mesh independent. As load on cutting tool increases the deformation increases.

\section{REFERENCES}

[1]. Johnston, E.L., 1950. Pressed log cutter. U.S. Patent 2,526,362.

[2]. TICA, Milan, and Branislav ČOLIĆ1-Slobodan ČAPLJAK. "Construction Solution and Estimate of Log Splitter." machine design 7, no. 3 (2015).

[3]. Minárik, M. and Hricová, J., 2015. Log Splitter Design and Construction. Drvnaindustrija: $\quad$ Znanstveničasopis $\quad z a$ itanjadrvnetehnologije, 66(1), pp.11-16.

[4]. Das, S.S., Tilekar, S.D., Wangikar, S.S. and Patowari, P.K., "Numerical and experimental study of passive fluids mixing in micro-channels of different configurations", Microsystem Technologies, Vol. 23, no. 12, pp.5977-5988, 2017.

[5]. Wangikar, S.S., Patowari, P.K. and Misra, R.D., "Numerical and experimental investigations on the performance of a serpentine microchannel with semicircular obstacles" Microsystem Technologies, pp.1-14, 2018.
[6]. Gidde, R.R., Pawar, P.M., Ronge, B.P., Shinde, A.B., Misal, N.D. and Wangikar, S.S., "Flow field analysis of a passive wavy micromixer with CSAR and ESAR elements", Microsystem Technologies, vol 25, no. 3, pp.1017-1030, 2019.

[7]. Shinde, A., Pawar, P., Shaikh, P., Wangikar, S., Salunkhe, S. and Dhamgaye, V., "Experimental and Numerical Analysis of Conical Shape Hydrodynamic Journal Bearing With Partial Texturing", Procedia Manufacturing, vol. 20, pp.300-310. 